\title{
DEFINING AND HIGHLIGHTING THE BEST QUALITIES OF A BRAND THROUGH ITS VISUAL IDENTITY
}

\section{${ }^{1}$ Tibério Gonzaga Figueiredo, ${ }^{1}$ Livia da Silva Oliveira, ${ }^{1}$ Suelânia Cristina Gonzaga de Figueiredo and ${ }^{* 2}$ David Barbosa de Alencar}

${ }^{1}$ Academic Department, University Center FAMETRO, Amazon-Brazil

2Institute of Technology and Education Galileo of Amazon (ITEGAM), Brazil

\begin{tabular}{l} 
ARTICLE INFO \\
\hline Article History: \\
Received $17^{\text {th }}$ February, 2020 \\
Received in revised form \\
$28^{\text {th }}$ March, 2020 \\
Accepted $02^{\text {nd }}$ April, 2020 \\
Published online $30^{\text {th }}$ May, 2020 \\
\hline
\end{tabular}

\begin{abstract}
The article deals with the application of designer tools to create the visual identity of a line of creative products. The logo, typography and color palette were defined for the composition of the elements that showed the personality of the brand to its customers. A systematic method was followed in the execution of the project, starting with the application of a briefing, and then the following steps were carried out: brainstorming, definition of elements, graphic editing and testing of possibilities. The result was a visual identity with sophisticated design outlining the idea of sophistication in the public eye.
\end{abstract}

Key Words:

Design; Visual identity; Logo.

*Corresponding author:

David Barbosa de Alencar,

Copyright (C) 2020, Tibério Gonzaga Figueiredo et al. This is an open access article distributed under the Creative Commons Attribution License, which permits unrestricted use, distribution, and reproduction in any medium, provided the original work is properly cited.

Citation: Tibério Gonzaga Figueiredo, Livia da Silva Oliveira, Suelânia Cristina Gonzaga de Figueiredo and David Barbosa de Alencar. "Defining and highlighting the best qualities of a brand through its visual identity”, International Journal of Development Research, 10, (05), 36227-36230.

\section{INTRODUCTION}

O artigo trata da aplicação de ferramentas do designer para a criação da identidade visual de uma linha de produtos criativos. A justificativa para o desenvolvimento desse trabalho foi de definir a personalidade de uma empresa de produtos personalizados que busca traduzir em seus produtos o estilo de vida, a filosofia, a maneira de ver o mundo de seus clientes. As pessoas querem produtos personalizados que os representem, embora esse tipo de produto possa ter um valor comercial maior. Nesse sentido a empresa Minha Essência busca criar produtos em pequena escala, individualizados, que expressem a essência do cliente. $\mathrm{O}$ artigo personalizado que represente traços marcantes de sua maneira de ser. Nesse aspecto é importante trabalhar com a identidade visual por vários motivos, mas um dos principais é que, com ela, é possível definir de forma visual, prática e "à primeira vista" quem é a empresa. Nesse sentido buscou-se a criação de uma identidade visual para a marca Minha Essência capaz de gerar forte sentimento de identificação, confiança, pertencimento e engajamento em relação à marca. Como principais elementos desenvolvidos para a identidade visual da marca Minha
Essência foram definidos a logomarca, a tipografia e a paleta de cores. A escolha das cores na definição de um projeto é de suma importância. Segundo Verity (1980) "Cor é mistério, definição iludida, é uma experiência subjetiva, uma sensação cerebral dependendo de três fatores relacionados e essenciais: a luz, um objeto e um observador."

\section{MATERIAL E MÉTODOS}

A criação da identidade visual da marca Minha Essência iniciou com a definição do conceito da marca e, na sequência seguiu cinco etapas distintas:

Briefing - A criação de um questionário (briefing) levantando pontos importantes para a empresa que devem ser levados em conta no momento da criação de uma identidade visual.

Brainstorming - Consiste em uma reunião em que várias pessoas se unem para ter ideias do que pode ser feito. Nesse momento, é importante que não existam preconceitos ou prejulgamentos sobre as ideias.

Definição de elementos - Após coletar todas as ideias, é hora de começar a moldar a identidade visual, definir elementos, 
cores e fontes. A escolha dos elementos está associada ao conceito da marca.

Edição gráfica - Chegou o momento de fazer a edição gráfica das ideias. Para a identidade visual da marca Minha Essência foi utilizado o Adobe Illustrator, software gráfico focado na edição de imagens vetoriais. Essa ferramenta faz parte do pacote Adobe e pode ser utilizada para a criação de ilustrações, logotipos, tipografias entre outros.

Teste de Possibilidades - Algumas opções de logotipo foram criadas e testadas em todos os tipos de materiais que a marca deverá utilizar: como cartões de visita, fachada da loja, redes sociais e aplicações em branco e preto, por exemplo. A escolha deverá ser baseada na funcionalidade da marca, e não apenas no "eu achei bonito", pois uma identidade visual com muitos efeitos de transição de cores, por exemplo, não terá uma boa aplicação em branco e preto.

\section{RESULTADOS E DISCUSSÃO}

O Conceito: A tarefa principal durante a criação da identidade visual foi definir o conceito que representasse a marca caracterizando sua visão e seus valores em um símbolo. A escolha da tipografia e da paleta de cores estão conectadas ao conceito da marca. A partir das informações obtidas no briefing chegou-se a um conceito para a marca Minha Essência (Fig. 1). Uma empresa, assim como uma pessoa, precisa de uma identidade própria, algo que a defina e a torne única. Presentes confeccionados de forma personalizada são únicos, assim como os momentos que eles marcam. Presentear quem amamos, representa muitas vezes demonstrar o carinho e a importância ímpar que a pessoa tem.

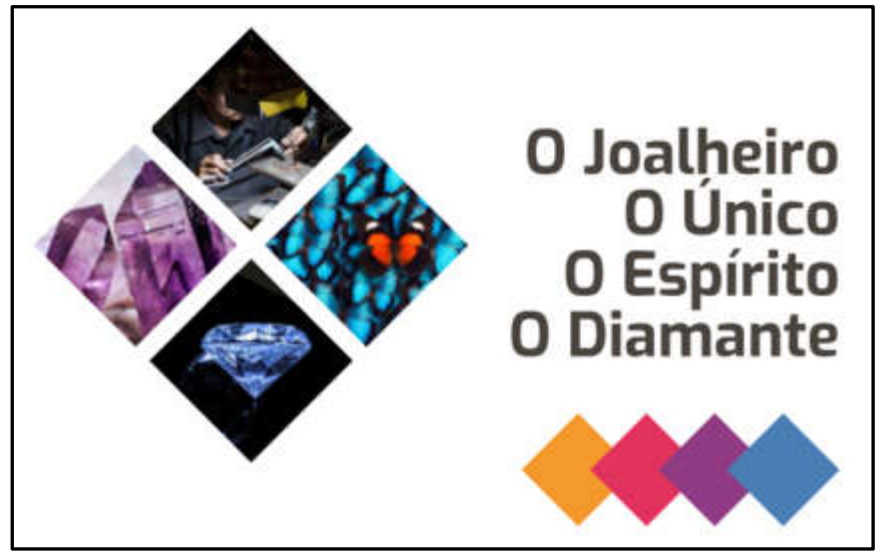

Fonte: Os autores, 2020.

Fig. 1. Conceito da marca Minha Essência

Os Elementos do Conceito: A composição do conceito tem os seguintes elementos constituintes:

$\boldsymbol{O}$ Joalheiro retorce o metal, derrete o ouro e esculpe a pedra bruta, revelando sua beleza, construindo presentes de maneira original.

$\boldsymbol{O}$ único, o ser diferente, não te faz ser solitário, ser diferente é ser inesquecível mesmo caminhando entre a multidão.

$\boldsymbol{O}$ cristal, tendo em conta a sua transparência é considerado um símbolo da transição entre o mundo dos sentidos e o mundo místico.
$\boldsymbol{O}$ diamante é a joia revelada pelo artesão, pedra resistente e exclusiva. Simboliza a elegância e a realeza, além de representar a durabilidade dos sentimentos.

A Logomarca: O elemento escolhido foi o diamante. Quando procuramos presentear com elegância, nada representa tudo isso tão bem quanto um diamante (Fig. 2). Singulares, originais e símbolo de sofisticação, assim como os sentimentos verdadeiros, os diamantes, são eternos.

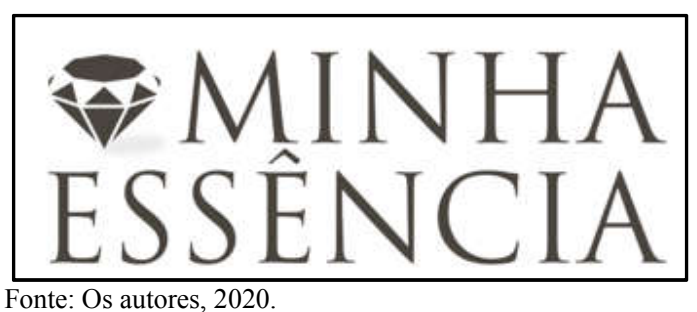

Fig. 2. Logomarca

A imagem do diamante foi incorporada ao nome da marca construindo um design ao invés de uma única imagem ser utilizada para representar a essência da empresa. Um design sofisticado delineando aos olhos do público a ideia de sofisticação.

A Tipografia: A fonte é o elemento responsável por dizer como sua marca é. Ela precisa estar em perfeita harmonia com os desenhos e cores, além de ser perfeitamente legível para o seu público. Diferentes famílias de tipografias imprimem emoções distintas aos clientes à primeira vista. Por exemplo, fontes que lembram escrita à mão remetem um ar de sofisticação e classe. Já as mais parecidas com a chamada "letra de forma" inspiram objetividade e clareza. A fonte está presente no logotipo da sua marca, como também em qualquer outra produção que envolva a comunicação visual. Para a marca Minha Essência foram escolhidas duas famílias tipográficas:

\section{TRAJAN + MINION PRO}

A fonte utilizada para a elaboração do logotipo foi a Trajan. Com formas baseadas nas letras utilizadas nos monumentos do império romano, seu nome se inspira no nome da Coluna de Trajano. Sua família tipográfica não possui letras minúsculas e suas formas alongadas e serifadas comunicam elegância, força e sofisticação. Apesar da boa leiturabilidade, a Trajan não se sai bem em longos blocos de texto, por isso, foi usada em associação a esta, a família tipográfica Minion Pro (Fig. 3), que também serifada, comunica valores similares mas por possuir um melhor espaçamento e minúsculas torna-se mais adequada para a leitura.

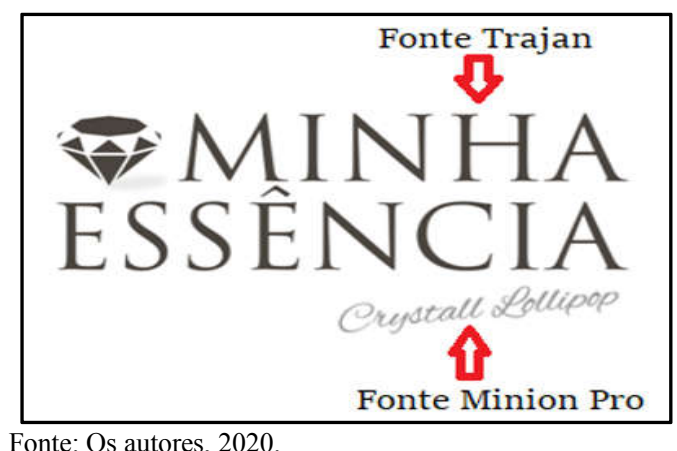

Fig. 3. Famílias tipográficas 
Grafismo e Paleta de Cores: O resultado final de um design gráfico denomina-se grafismo, e é uma unidade por si mesma, embora esteja composto por uma infinidade de elementos diferentes. As formas geométricas escolhidas para acompanharem as aplicações visuais da marca, são formadas por conjuntos de quatro quadrados, inclinados em $45^{\circ}$ representando a forma simplificada do diamante, símbolo da marca (Fig. 4).

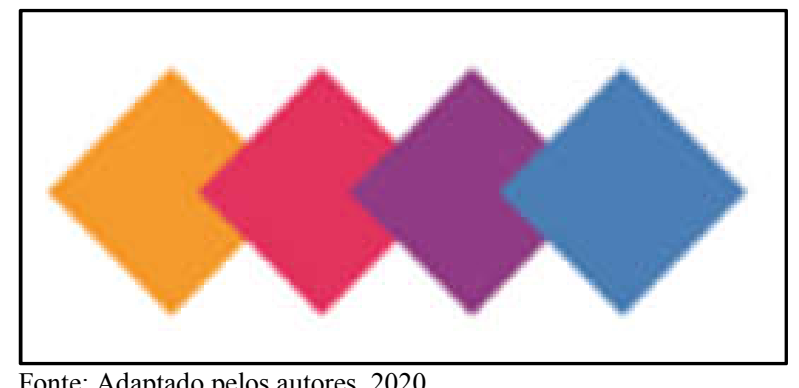

Fig. 4. Quadrados inclinados em $45^{\circ}$ representando um diamante

As cores exercem um papel fundamental no processo de interpretação de sensações no cérebro. Despertam sentidos, ativam memórias e representam conceitos de forma poderosa. Por isso, precisam ser muito bem analisadas antes de aplicadas a identidade visual de uma marca. Nesse sentindo definiu-se para marca a identidade visual da marca Minha Essência a paleta de cores: laranja, magenta, roxo e azul (Fig. 4). A escolha dessa paleta de cores buscou expressar o conceito da marca Minha Essência, com o significado único de uma cada uma das cores (Quadro 1) através das quais seus clientes sejam impactados de forma positiva, pois, segundo um conceito tradicional do neuromarketing, "Se uma boa cor vende, a cor certa vende melhor".

\section{Quadro 1. Cores e significados}

\begin{tabular}{|ll|}
\hline Cor & Significado das cores \\
\hline LARANJA & $\begin{array}{l}\text { significa alegria, vitalidade, prosperidade e } \\
\text { sucesso. }\end{array}$ \\
\hline MAGENTA & $\begin{array}{l}\text { representa o mistério, expressa sensação de } \\
\text { individualidade e de personalidade. }\end{array}$ \\
\hline ROXO & $\begin{array}{l}\text { nobreza, riqueza e sucesso. A cor está também } \\
\text { associada à sensibilidade e inovação. }\end{array}$ \\
\hline AZUL & confiança, segurança e calma. \\
\hline
\end{tabular}

Fonte: Adaptado pelos autores, 2020.

E, quando se pensa em persuasão, trabalhar a emoção pode trazer resultados significativos. E nada, nem mesmo imagens, mexe mais com as emoções do que as cores. Após a definição de todos os elementos a logomarca Minha Essência foi definida de forma completa (Fig. 5). A representação do conceito da marca, sua filosofia, as ideias e sentimentos que inspiraram sua a idealização do conceito, representada na arte final de sua logomarca.

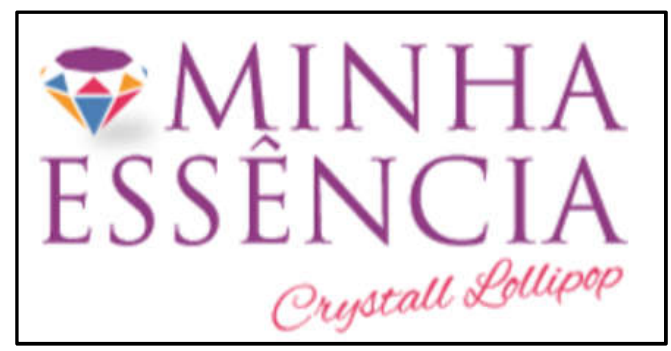

Fonte: Os autores, 2020.

Fig. 5. Logomarca Minha Essência
Por fim, foi testada a aplicação da identidade visual em vários itens de apresentação da marca, esse processo é importante para uma análise final antes da aprovação da marca, afinal será um guia definitivo do negócio (Fig. 6). Adaptar os componentes gráficos para que possam ser utilizados em diferentes fundos. Isso garante que o conjunto visual não contraste negativamente com o plano de fundo, caso seja necessário fazer alguma alteração.

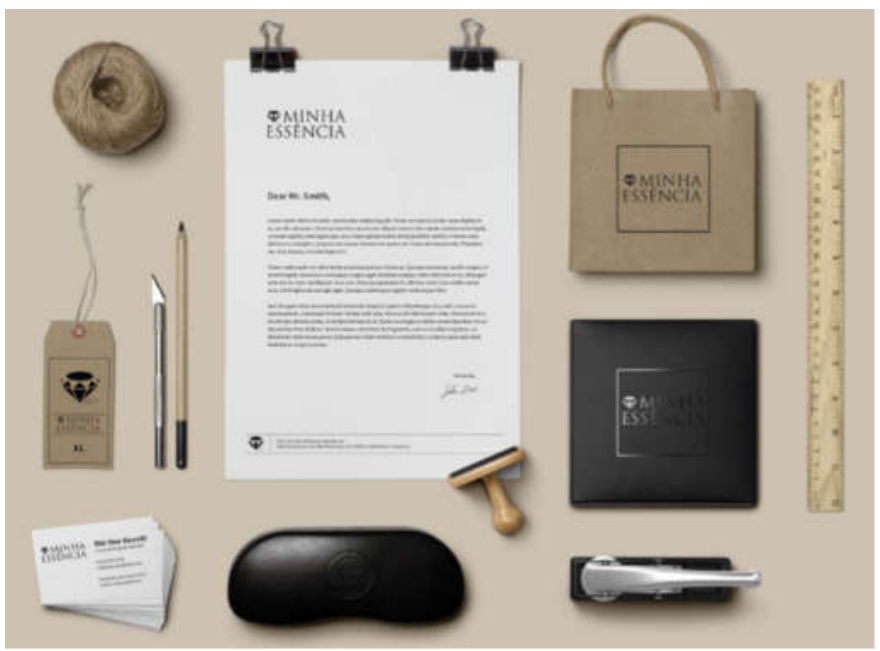

Fonte: Os autores, 2020.

Fig. 6. Planejamento gráfico para alguns meios de divulgação da marca

O resultado foi satisfatório, atendeu as expectativas do cliente que, iniciará as atividades de seu negócio de uma forma consolidada, firmando sua identidade em cada produto desenvolvido pela Minha Essência. Muitas vezes uma marca já consolidada reformula sua identidade visual por diversos fatores. Podemos observe dois exemplos de identidade visual que se renovou com muito sucesso.

Starbucks: Em 2011 a conhecida franquia de cafés Starbucks fez mudanças significativas na identidade visual de seus produtos. A empresa passava por um período de recessão, e consequentemente, diminuição no número de vendas. A empresa então tomou a decisão de explorar outros mercados, vendendo diferentes produtos (canecas, camisetas, sorvetes...) inclusive fora de suas lojas. Por conta dessa decisão, a palavra coffee (café) foi removida do logo (Figura 7).
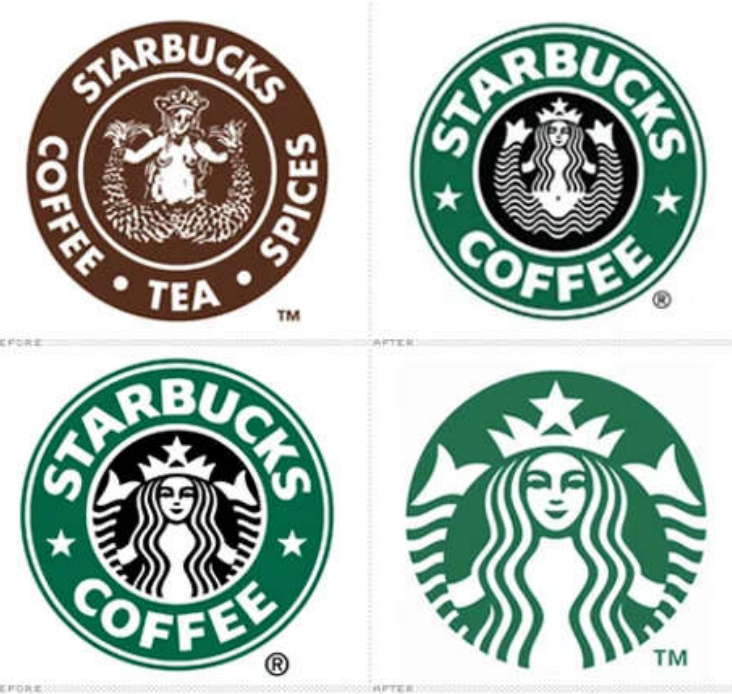

Fonte: blog.wedologos.com.br. Acesso em: 2 maio. 2020.

Fig. 7. Identidade visual da Starbuks e suas modificações 
Uma equipe criativa teve então a missão de renovar a imagem da marca, repaginando também sites, embalagens, e todos os canais de comunicação. O resultado? Um aumento progressivo no número de vendas, expansão de mercado, e estabelecimento dela como umas das top of mind no segmento de cafeterias.

Natura: Em meados dos anos 2000, a marca resolveu investir em pesquisa e desenvolvimento, renovar suas instalações, no e-commerce, e também investir no mercado exterior. Nesse novo cenário a empresa buscou a renovação de sua identidade visual, o foco foi a busca por uma imagem com um conceito de uma personalidade elegante, ativa e atualizada. A partir daí a empresa passou por um processo de reformulação da identidade visual. $\mathrm{O}$ resultado foi uma logo com mais movimento, leveza e clareza, adequado a proposta de crescimento da empresa, e mais atrativo ao público alvo da marca.
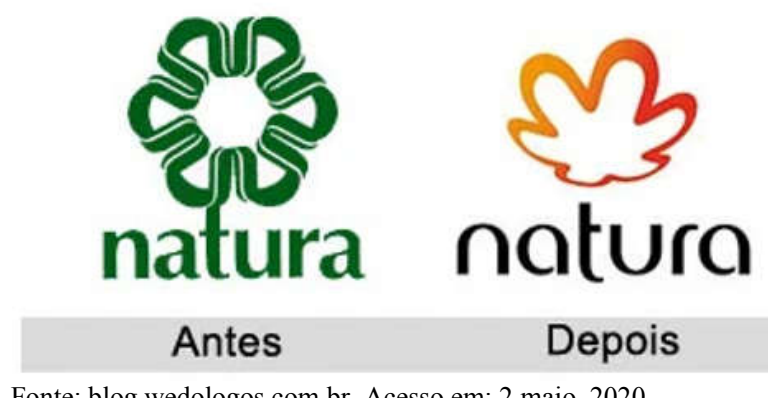

Fig. 8. Modificação da identidade visual da marca Natura.

O posicionamento de uma empresa deve ser traduzido em todos os pontos de contato entre a marca e o consumidor. É por isso que a identidade visual é tão importante: ele é o rosto, a face, a representação da personalidade de uma marca.

\section{Conclusão}

A criação de uma identidade visual passa por um processo minucioso e cheio de critérios. Deve ser bem estudada e trabalhada. Seu desenvolvimento requer avaliação completa de aplicações e formatos ideais para sua apresentação. Pode-se afirmar que a identidade visual é toda a linguagem comportamental que a empresa adota como padrão para o seu relacionamento com os clientes. Através da leitura visual, o cliente reconhece todo o universo de uma empresa, permitindo conceituar o seu negócio, e identificar se as expectativas serão devidamente atendidas.
Ao definir a voz que a sua marca terá no mercado, fica muito mais simples desenhar um rosto para ela, principalmente uma face que esteja em harmonia com essa forma de se comunicar e com as expectativas do cliente.

\section{REFERÊNCIAS}

AlveS, A. L.; SILVA, J. C.; PASChOARELli, L. C. A importância das cores no desenvolvimento e aplicação nas identidades visuais presentes no mercado - Uma revisão. Revista Logo. Florianópolis, v.4, n. 2. 2015. Disponível em: http://incubadora.periodicos.ufsc.br/ index.php/eRevistaLOGO/article/view/5451/5355.

FRANZATO, C. O Processo de criação no design conceitual. Explorando o potencial reflexivo e dialético do projeto. Tessituras e Criação. São Paulo. n. 1. mai, 2011. Disponível em: https://revistas.pucsp.br/ index.php/tessituras/article/view/5612.

HELlER, E. A Psicologia Das Cores - Como As Cores Afetam a Emoção e a Razão. Editora GG Basil. 2012.

Marcas de luxo: sensação de poder e destaque social. Revista Logo. Florianópolis, v.1, n.1, 2010. Disponível em: http://incubadora.periodicos.ufsc.br/index.php/eRevistaL OGO/article/view/2820/3336.

MOTA, Gustavo. 24 exemplos de identidade visual renovada que deram certo. Disponível em: https://blog.wedologos. com.br/design-grafico/identidade-visual/exemplos-deidentidade-visual/. Acesso em: 02 maio. 2020.

Princípios e práticas. 2 ${ }^{\mathrm{a}}$ ed. Editora GG Brasil, 2019.

Schumacher, T., \& Mayer, S. (2018). Preparing Managers for TurbulentContexts: Teaching the Principles of Design Thinking. Journal of Management Education, 42(4), 496.

STRUNCK, GilbertoL.T. L. Como criar identidades visuais para marcas de sucesso: um guia sobre o marketing das marcas e como representar gra0icamente seus valores. 3 ed.Rio de Janeiro: Rio Books, 2007.

TEIXEIRA, J. M.; GARCIA, L. J.; MERINO, E. A. Brand target: Brand'shierarchy and management. Revista Logo. Florianópolis, v.7, n.3. 2018 - ISSN 2238-2542 http://doi.org/10.26771/e-Revista.LOGO/2018.3.05.

Disponível em: http://incubadora.periodicos.ufsc.br/index.php/eRevistaL OGO/article/view/5458/5347.

VERITY, Enid. Color Observed. 1st ed. Van Nostrand Reinhold, 1980.

VIANNA, Maứcio et al. Design thinking: inovạ̃o em neǵcios. Rio de Janeiro: MJV Press, 2012. 162p.

VICKRESS, A.; DABNER, D.; STEWART, S. Curso de design gráfico 